\title{
DESIGN OF A METHODOLOGY FOR IDENTIFYING AND SELECTING THE BEST ALTERNATIVE IN ACQUIRING THE INFORMATION SYSTEM FOR A COMPANY
}

\author{
Diana Consuelo Gómez Muñoz \\ Commercial support engineer \\ Instrumentos y Controles S.A. \\ E-mail: dicogom@gmail.com \\ Mario Castillo \\ Department of Industrial Engineering \\ Universidad de los Andes \\ Bogotá, Colombia \\ E-mail: mcastill@uniandes.edu.co
}

\begin{abstract}
This article presents a Decisions Analysis methodology using qualitative and quantitative criteria supported in probabilistic models, risk analysis and Analytic Hierarchy Process (AHP), for selecting the best alternative in acquiring the adequate information system for the company's interests.
\end{abstract}

Keywords: Decisions Analysis, Analytic Hierarchy Process (AHP), influence diagram

\section{Introduction}

The company's accelerated growth has produced some trouble in handling the information. Indeed, the current information system has reached a high level of uselessness and it is not prepared for the company's current volume and features. As a result, the need to migrate to another system that fulfills the company's current requirements has been detected.

This is a complex decision problem because it involves a corporative change, which implies high investment of capital, specialization and commitment. To take the best decision on this point guarantees the maximum benefit in the change strategy, minimizes operating costs and optimizes implementing, supporting and controlling processes. All this also guarantees continuous improvement and alignment between this informatics' strategy with company's corporate strategies.

To solve the problem, a methodology for identifying and selecting the company's best alternative in acquiring the information system was designed, which takes as reference the Information Systems' life cycle proposed by Chiesa (2005) and the Decisions' Analysis methodology proposed by Castillo (2006).

The methodology is composed by three phases. Phase 1: Detect the need for change in the Information System. Phase 2: Select an Implementation solution. Phase 3: Choose a Supplier. These two last phases are related with an important decision and therefore require a specific procedure to support that decision.

\footnotetext{
${ }^{*}$ Corresponding author
} 


\section{General methodology}

The following figure is a graphical representation of the proposed methodology:

Phase 1:

Detect need for change in current information System

Phase 2:

Select an implementation solution
Phase 3:

Choosing a supplier

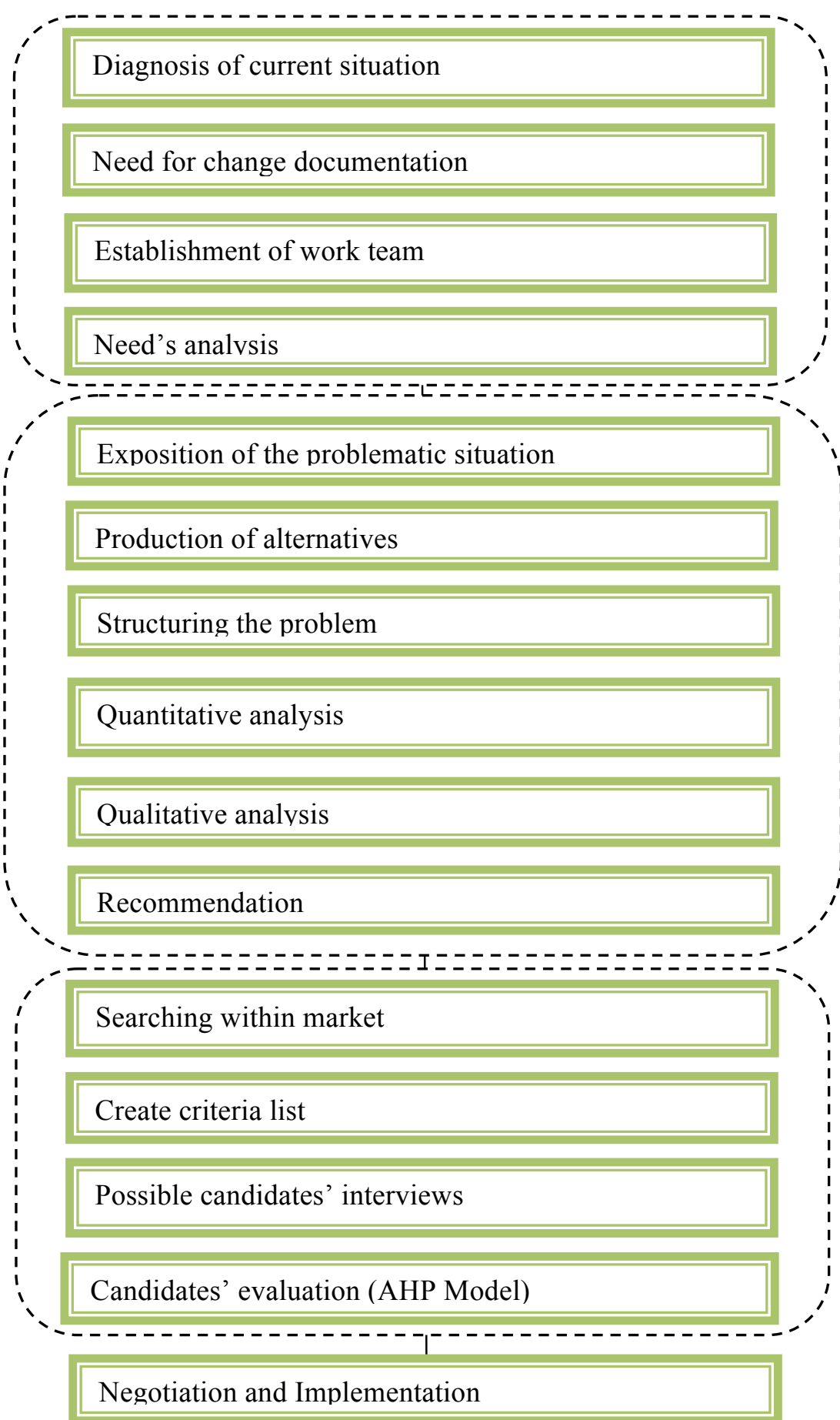

Figure 1. Methodology for selecting the best alternative in acquiring the information system for the company. Personal source. 


\subsubsection{Current situation diagnosis}

Given the fact that companies are as efficient as their own processes, a detailed diagnosis by processes of the company's current situation was made, in relation to its information management needs and support tools.

The analysis of the diagnosis by processes of the current situation allowed us to cover every area of the company. Employees and executive directors, who perform each process, participated.

\subsubsection{Need for change documentation}

After finishing the current situation diagnosis, the need for change the information system was formally declared in an internal document, which contains description of the following items: description, deviation, impact, changes, possible causes and the preventive or corrective action.

\subsubsection{Establishment of the Work team}

The company considered that it has itself enabled staff to take the decisions related to the information system's change. This task was assigned to a work team constituted by the supervisors of different company's areas leaded by the general manager and the informatics director, who could evaluate in conjunction technical aspects, user areas' needs, costs, times and risks, among others.

The group was called PROSIS, and was created to support the new information system's decision making process.

\subsection{Phase 2: Select a solution}

The company concluded that needs to integrate a new information system. In this methodology's phase it must be decided what kind of solution to choose.

\subsubsection{Structuring the problem}

A brainstorm took place in the PROSIS group to define relevant aspects to decide which the most appropriate solution is for the company. As a result of this activity, the following list of relevant aspects was brought out:

Table 1. Relevant aspects for selecting the most appropriate solution. Personal source based on analysis

\begin{tabular}{|l|l|}
\hline Aspect & \multicolumn{1}{|c|}{ Description } \\
\hline Economic or cost & $\begin{array}{l}\text { It refers to the total cost of all different alternatives, measured by the Net Present } \\
\text { Value (NPV). This economic aspect depends on external costs as licenses, } \\
\text { development, updates and infrastructure, and also on internal costs as required } \\
\text { dedication of the company's resources and charges associated to the impact of } \\
\text { the company's new information system. }\end{array}$ \\
\hline $\begin{array}{l}\text { Functionality or } \\
\text { adaptability }\end{array}$ & $\begin{array}{l}\text { Functionality is the alternative's degree of adhesion and adaptation to } \\
\text { company's business processes and its information needs. }\end{array}$ \\
\hline Implementation time & $\begin{array}{l}\text { It is the time between the software alternative acquisition's date and the moment } \\
\text { it gets going suited already for users. The impact of the implementation of the }\end{array}$ \\
\hline
\end{tabular}




\begin{tabular}{|l|l|}
\hline Security & company's solution depends remarkably on this aspect. \\
\hline $\begin{array}{l}\text { The impact inside the } \\
\text { company }\end{array}$ & $\begin{array}{l}\text { Measures the right functionality level of each alternative along all its } \\
\text { functionalities. } \\
\text { to the new system (depending on each alternative), as delays in executing } \\
\text { processes or information loss, among others. }\end{array}$ \\
\hline Ease of updating & $\begin{array}{l}\text { It refers to the frequency and ease with which the user can have access to the } \\
\text { new and updated versions of each alternative, quickly and reliably. }\end{array}$ \\
\hline Scalability & $\begin{array}{l}\text { It is the capacity that must have each alternative to increase their output without } \\
\text { redesigning in case of enlargement of the number of requirements due to the } \\
\text { company's growth or expansion. }\end{array}$ \\
\hline $\begin{array}{l}\text { Experiences and } \\
\text { successful cases in } \\
\text { the sector }\end{array}$ & $\begin{array}{l}\text { Analyze recent implementations of each alternative and find out whether they } \\
\text { are successful or not. }\end{array}$ \\
\hline
\end{tabular}

To produce alternatives that solve the previously structured problem, the following sequence of activities was designed: 1) Do market research, 2) Define decision's criteria and important politics, 3) Make a solutions' comparative and 4) Create the first filter.

After each of these activities, we achieve the following alternatives in our study:

Alternative 1: Buy an ERP standard software package

Alternative 2: External Implementation and Development

Alternative 3: Internal Development.

\subsubsection{Quantitative Analysis}

In the quantitative analysis the first step consisted in building a deterministic model in Excel for calculating the three generated alternatives' NPV costs, and observing its behavior for five years. To calculate these costs were considered, for each alternative, the following variables: Initial Investment, license costs, development costs, infrastructure cost, operating costs, administration and support costs, training costs, internal staff costs, other costs linked to the SI's emergence in the company and implementation time, among others.

Later, from the built deterministic model, the random behavior of some variables, as problem's uncertainty sources, was incorporated to the analysis through an influence diagram. These variables are described next:

Table 2. Random type variables considered in quantitative analysis. Personal source based on analysis. 


\begin{tabular}{|c|c|c|}
\hline Variable & Type & Description \\
\hline Inflation & Random & $\begin{array}{l}\text { Triangular }(0.04,0.05 \text {, } \\
0.06)\end{array}$ \\
\hline Time to repair damage (hours) & Random & Triangular $(5,3,1)$ \\
\hline ERP's Initial Investment & Random & $\begin{array}{l}\text { Triangular }(190 ", 170 ", \\
150 ")\end{array}$ \\
\hline External Dev.’s Initial Investment & Random & $\begin{array}{l}\text { Triangular }(170 ”, 150 ”, \\
130 ")\end{array}$ \\
\hline ERP's spent time rate & Random & Normal $(30 \%, 10 \%)$ \\
\hline External Dev.'s spent time rate & Random & Normal $(50 \%, 10 \%)$ \\
\hline ERP's number of incidents per year & Random & Poisson (3) \\
\hline External Dev.'s number of incidents rate per year & Random & Poisson (50) \\
\hline
\end{tabular}

The random variables of Excel's deterministic model were incorporated to the influence diagram described in figure 2 and exported to Excel. Furthermore, alternatives' NPV variables were exported from Excel to DPL.

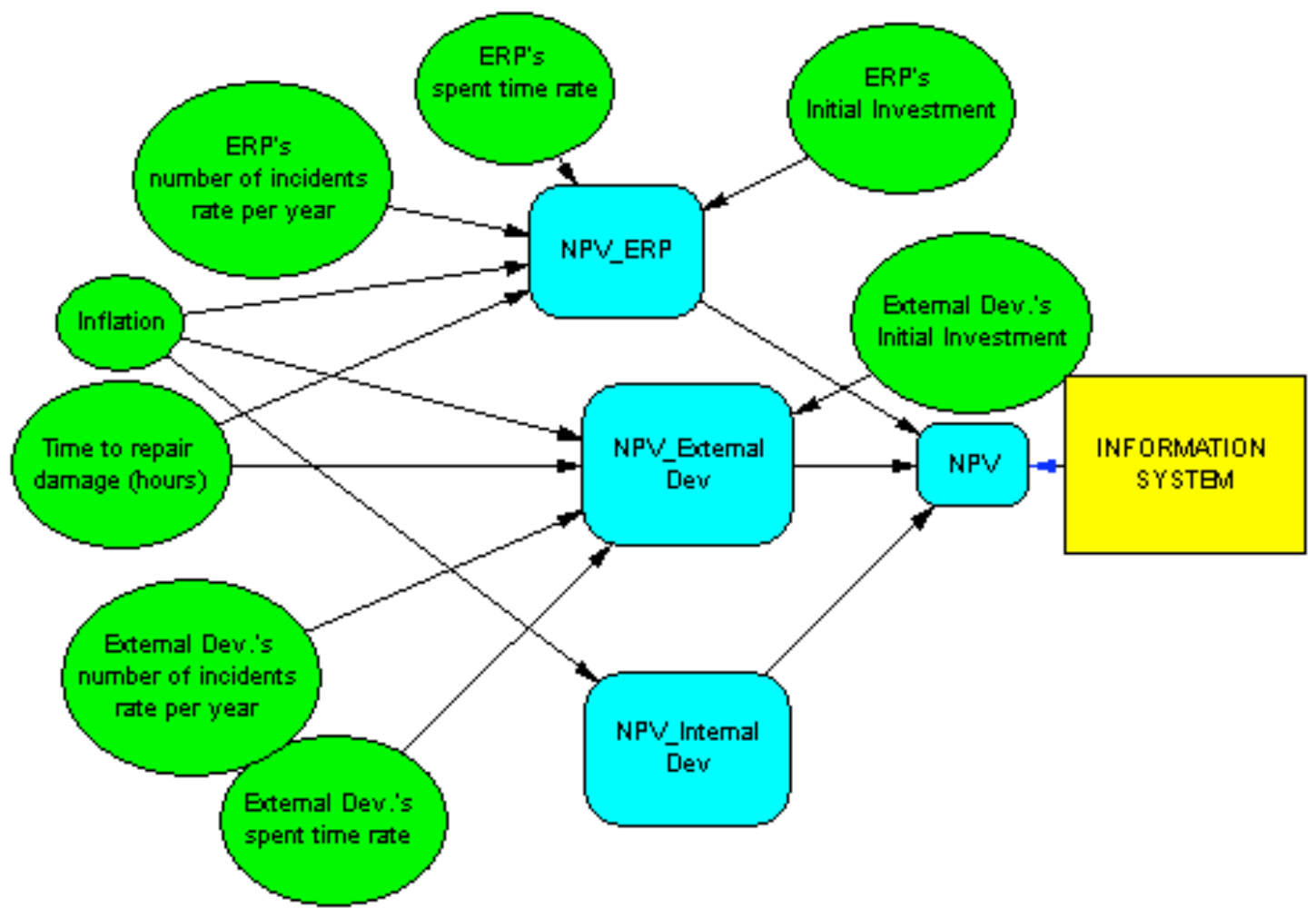

Figure 2. Influence Diagram. Source: DPL.

In figure 2, we observe that NPV is the performing variable, and "INFORMATION SYSTEM" is the decision's variable, which represents the available solution alternatives. Source: DPL. 
After evaluating the DPL influence diagram of figure 2, we found out that the best choice to minimize costs is to opt for acquiring the ERP package, what means that the new information system cost would be equal to 576.626 millions of pesos ${ }^{1}$. Figure 3 illustrates this point.

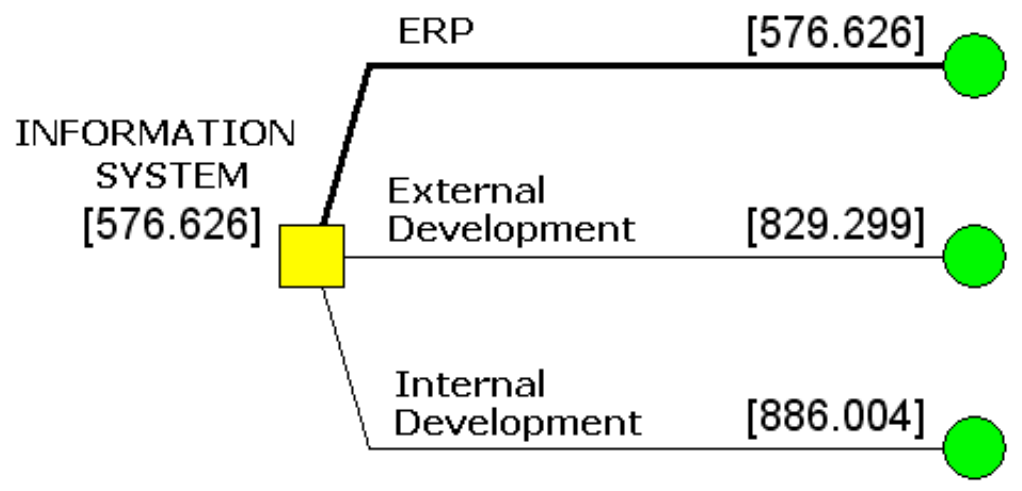

Figure 3. Optimal politics. Source: DPL.

Figure 4 expresses the probability that the best alternative cost takes on an approximate value of 570 millions of pesos is $20 \%$, according to the optimal politics. At the same time, the probability that this value can take on a maximum value of 635 millions of pesos is $2 \%$. Finally, the best alternative can take on a minimum value of 520 millions of pesos with a probability of $2 \%$.

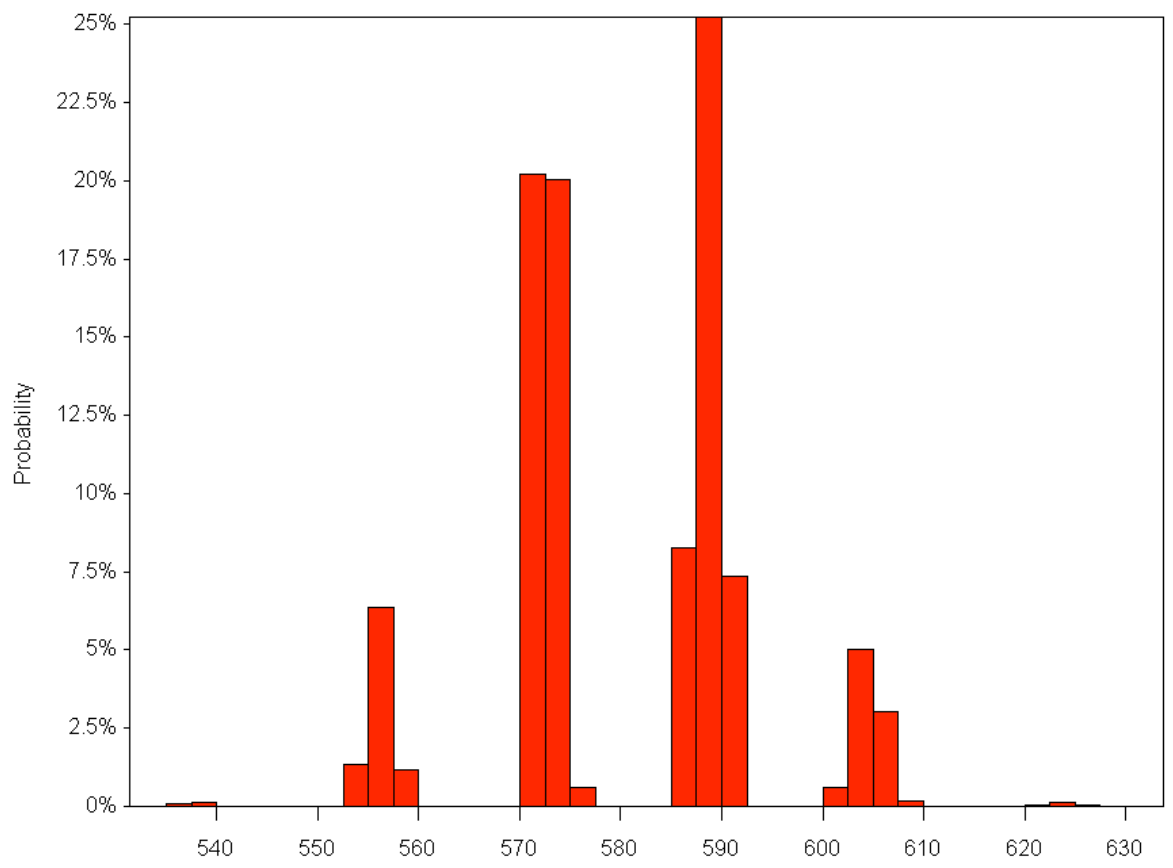

Figure 4. Risks' distribution. Source: DPL.

${ }^{1}$ Equal to 264,20 US dollars. According to Universal Currency Converter, www.xe.com/ucc/, a Dollar costs 2.182,5 Colombian Pesos. Retrieved May 29, 2009. 


\subsubsection{Qualitative Analysis}

Qualitative analysis' goal is to weight some variables difficult to quantify but very important when selecting the best alternative.

Step 1: Problem structuring

Goal: To obtain the best alternative for the company's information system solution.

Factors: The factors to be evaluated are implementation impact in the company, successful implementation cases in the sector, ease of updating, software's security and adaptability or functionality, and its scalability. Description all these factors on chart 1 .

Alternatives: The alternatives to study are:

Alternative 1: Buy an ERP standard software package Alternative 2: Implementation and External Development Alternative 3: Internal Development

The following figure describes the alternatives' Hierarchy in regard to the aspects to ponder:

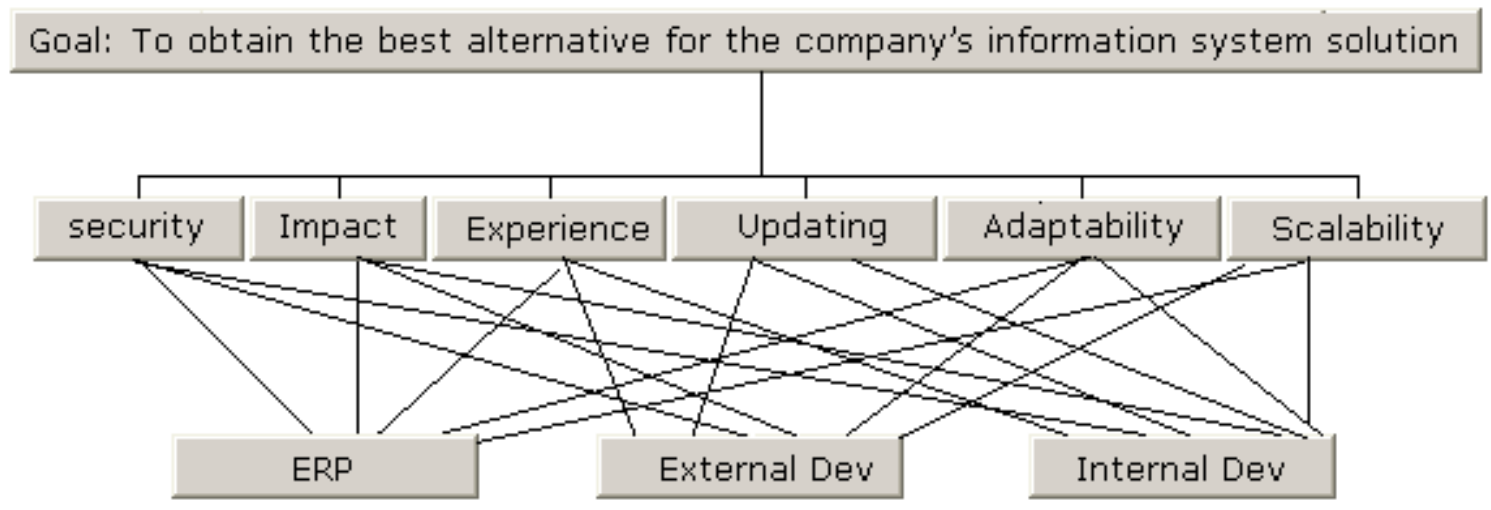

Figure 5. Qualitative Model Hierarchy. Source: Expert Choice.

Step 2: Matrices building

Pairwise comparison matrices, useful to the model as input data, were elaborated by the PROSIS group in a workshop while following Saaty's evaluation scale.

Step 3: Estimation

We used Expert Choice to estimate each element's relative weights with respect to the element of the immediately higher level. As a result, we had what is shown in Figure 6: 
Priorities with respect to:

Goal: To obtain the best alternative for the company's information sys.

Adaptability

Scalability

Security

Updating

Impact

Experience

Inconsistency $=0,05$ with 0 missing judgments.

Priorities with respect to:

Goal: To obtain the best alternative for the company's information syste >Experience

\section{ERP}

Externnal Dev

Internal Dev

Inconsistency $=\mathbf{0 , 2 0}$

with 0 missing judgments.

Priorities with respect to:

Goal: To obtain the best alternative for the company's information syste $>$ Security

ERP

Externnal Dev

Internal Dev

Inconsistency $=\mathbf{0 , 0 6}$ with 0 missing judgments.

Priorities with respect to:

Goal: To obtain the best alternative for the company's information syste $>$ Adaptability

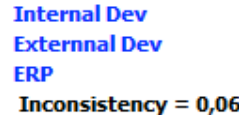

Priorities with respect to:

Goal: To obtain the best alternative for the company's information syst >Scalability

ERP

Externnal Dev

Internal Dev

Inconsistency $=0,04$ with 0 missing judgments.

Priorities with respect to:

Goal: To obtain the best alternative for the company's information syste > Impact

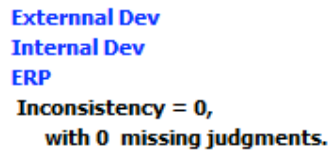

Priorities with respect to:

Goal: To obtain the best alternative for the company's information syste $>$ Updating

ERP

Externnal Dev

Internal Dev

Inconsistency $=\mathbf{0 , 0 3}$

with 0 missing judgments.

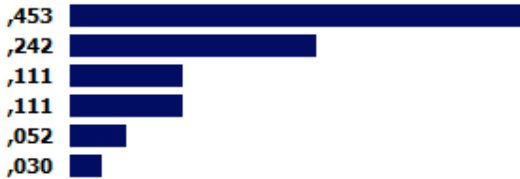

772

,173

, 055

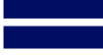

,731

,188

081

, 279

,072

,637

,258

,105
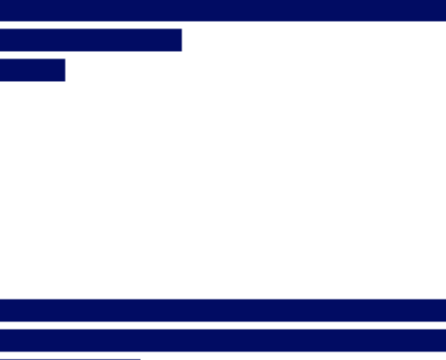

, 429

,143

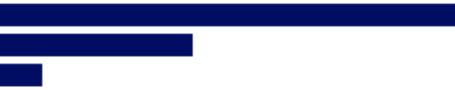


Synthesis with respect to: Goal: To obtain the best alternative for the company's information system solution.

Overall Inconsistency $=, 05$

\begin{tabular}{ll|l|l|l|}
\hline ERP &, 372 & & \\
Internal Dev &, 370 & & \\
Externnal Dev &, 258 &
\end{tabular}

Figure 7. Alternatives select result. Source: Expert Choice.

In figure 7, we observe that the best alternative, according to this model, is the EPR package choice. However, ERP package's alternatives and the internal development only differ on a $0.2 \%$, which is a tiny margin of difference.

\subsection{Phase 3: choosing a supplier}

After having decided what kind of solution to implement, we pass onto this stage, where the objective is to identify the supplier that best goes with the company's needs and the solution selected. The following are the activities established of this phase: Searching within the market, Criteria List, Candidates' interviews, Candidates' evaluation.

\subsubsection{Searching within the market}

This activity's aim consists in looking for available ERP in the market. To achieve this task, internet, software presentations and professional magazines were consulted, and professionals of other companies were also consulted to have some advice from. This, intending to create a list of all ERP found suppliers. As a second step of this activity, some of these suppliers were contacted and asked to give out all the possible information. The activity was developed by the decision maker group.

Soon after, those ERP that did not cover every company's area requirements were removed from the list. Therefore, the suppliers' quantity was reduced to 5 candidates, bearing in mind all what it has been said and the successful applications in companies of the sector:

- $\quad$ SAP B Business One: ERP y CRM for Small and Medium Companies

- $\quad$ UNO-ENTERPRISE: Integral Corporate Information System - ERP

- $\quad$ QAD Enterprise Applications: ERP Solution

- $\quad$ MICROSOFT DYNAMICS AX: ERP Modular Solution for Medium and Large Company

- $\quad$ SOFTLAND ERP: The Software Corporate Solution for Large Company

\subsubsection{Criteria list}

This stage's goal consists in making a list of comparison points that can be appropriated for company's needs. The list will be the work's base on the final evaluation. The Chiesa, F. model (2005) was taken as a reference for elaborating criteria. This model was adapted to the company's particular needs. The criteria listed are divided in five categories: Product's functional aspects, technical aspects, supplier features, service features and economic aspects.

\subsubsection{Candidates' interviews}

At this point the team arranged interviews the candidates. This stage's objective was to collect needed information and to establish criteria enough to make possible to PROSIS group to evaluate candidates in the light of criteria list. 
Each criterion was classified with a value of 1 to 4 as follows: $1=$ Bad, $2=$ Regular, $3=$ Good, $4=$ Very Good. Later, values obtained from criteria of a same group were added, with which the general group classification was obtained. This process was repeated in the 6 groups on evaluation and in the 5 ERP already evaluated. The results were averaged, what conferred a qualification that was helpful as a base for elaborating pairwise comparison matrices.

\subsubsection{Candidates' Evaluation}

A Hierarchic Analytical Process was built to select the ideal ERP system supplier, in which the initially described decision's criteria were taken into account.

Step 1: Problem structuring

Goal: To chose the best ERP supplier

Factors: Functional aspects, technical aspects, supplier aspects, service aspects and economic aspects. They all have been described previously.

The alternatives to study are:

Alternative 1: SAP® Business One

Alternative 2: UNO-ENTERPRISE

Alternative 3: QAD Enterprise Applications

Alternative 4: MICROSOFT DYNAMICS AX

Alternative 5: SOFTLAND ERP

The following figure describes this model's hierarchy. In the first level, we observe the aspects or factors, and in the second one, we have the alternatives:

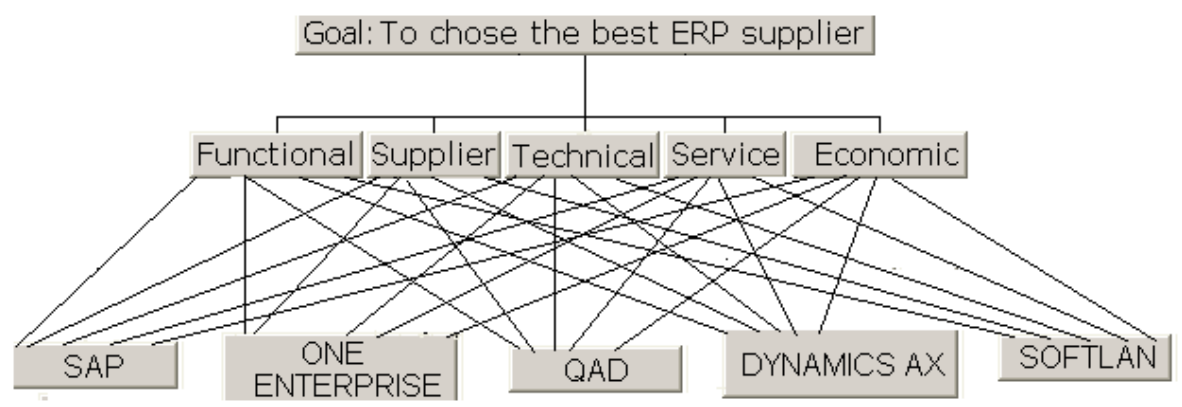

Figure 8. AHP Model Hierarchy for supplier evaluation. Source: Expert Choice.

Step 2: Matrices building

Pairwise comparison matrices that were useful to the model as input data, were elaborated by PROSIS group from qualifying each group of aspects, and from the information acquired on the interviews stage.

Step 3: Estimation

We used Expert Choice to estimate each element's relative weights with respect to the element of the immediately higher level. As a result, we had what is shown in Figure 9: 
Priorities with respect to:

Goal: To chose the best ERP supplier

Functional

Technical

Economic

Supplier

Service

Inconsistency $=0,03$

with 0 missing judgments.

Priorities with respect to:

Goal: Evaluar Proveedor de ERP

$>$ Functional

SAP

Dynamics AX

Softland

QAD

One Enterprise

Inconsistency $=0,33$

with 0 missing judgments.

Priorities with respect to:

Goal: Evaluar Proveedor de ERP 2 Technical
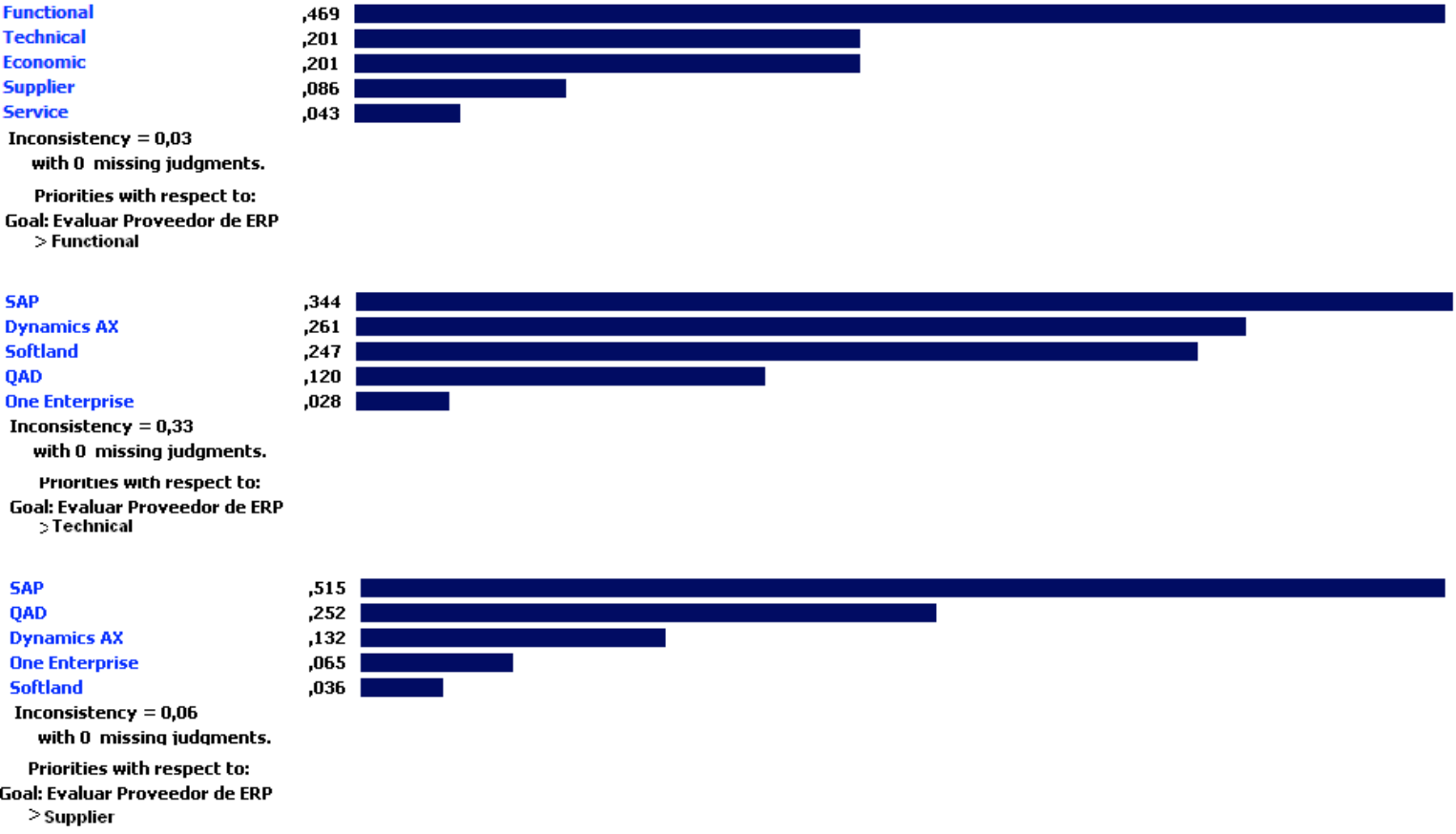
Figure 10. Alternatives' select result. Source: Expert Choice.

According to the built AHP model, SAP is the best option in the particular case of the company's ERP Software supplier selection with a weight of $31 \%$, followed by Softland with $23 \%$ of weight.

\subsection{Negotiation and implementation}

Even if PROSIS' decision maker group must keep on the chosen system's negotiation and implementation, this stage is out of reach in the methodology described.

\section{Conclusions}

About Methodology use:

- Company's current situation diagnosis made by processes allowed us to have a vast, clear and precise definition of the company's requirements in regard to Informatics support tools.

- In correspondence with the results of the quantitative analysis, that was made to carry out the selection of the information system's solution best alternative, we conclude that buying an ERP package is the best alternative from an economic point of view.

- Concerning to the qualitative evaluation results, the AHP model allows us to evaluate the alternatives with respect to aspects as adaptability, security, scalability, updates, impact and experience.

- To elaborate quantitative and qualitative analysis concurrently to make one decision, allowed us to embody all those non-quantifiable aspects, important for the decision maker, and also to compare them with the economic aspect.

- $\quad$ From the results obtained in methodology's phase 3, which had for goal to chose the best software supplier, we conclude that combining the evaluating tools of the traditional suppliers with others like the hierarchy analytical process provides a more reliable evaluation, since it allows to allocate weights to select evaluating criteria, bearing in mind information and impact caused by suppliers in the decision maker group.

- In qualitative evaluation results, the AHP model showed that the ERP SAP alternative is the best option when evaluating all suppliers' alternatives with respect to functional, economic and technical aspects, as well as suppliers and service features. Sensibility analysis showed that varying aspects as functionality does not affect the results.

- The main contribution of this kind of decision making methodologies is that they allow us to allocate a sensibility analysis of variables of interest, making projections in different spheres.

About the company's experience:

- Through the general proposed methodology use in the company, the Information system acquisition process was accomplished in a organized and structured way, avoiding dead times of all those who made part in this project and achieving the objectives within deadlines. 
- The decision maker team formation, a multidisciplinary group that fits to the project needs, has demonstrated that it is possible to work in group in an organized way, with which everybody provides with experience and ideas.

- The decision makers' commitment and the company's executive directors unconditional support is an essential aspect in the development of this kind of methodology in a corporative level.

- The methodology reduced the time in making decision and participants' process domain.

- The methodology increased: Analysis deepness, participation level, decision's quality, secured and gratifying results, and the satisfaction of working in group process.

\section{REFERENCES}

Castillo, M. (2006); Toma de decisiones de las empresas: Entre el arte y la técnica, metodología, modelos y herramientas (1rst Ed.). Bogotá, Colombia: Ediciones Uniandes.

Chiesa, F (2005). Metodología Para Selección De Sistemas ERP. Centro de Ingeniería del Software e Ingeniería del Conocimiento (CAPIS). Retrieved May 15, 2008, from http://www.itba.edu.ar/capis/webcapis/planma.html

Clemen, R.T. (1996). Making Hard Decisions An Introduction to Decision Analysis (2nd Ed.). Pacific Grove, USA.:Duxbury Press.

Del Valle, J. (s.f.) Introducción A La Teoría De Decisiones. Retrieved May 20, 2008, from http://ingsistemas2.javica1.com/Decisiones/IntroDecisiones.html

Guerrero, J. (2006). ERP al alcance de las PYMES. Pequeñas y Mediana empresas PYMES. Retrieved June 7, 2008, from http://www.gestiopolis.com/recursos/documentos/fulldocs/ger1/erppymes.htm

Guerrero, R. (2008). Problemas Operacionales, Teoría De La Toma De Decisiones O Programación Matemática. Producción, procesos y operaciones. Retrieved May 23, 2008, from http://www.gestiopolis.com/administracion-estrategia/problemas-operacionales-teoria-de-la-toma-de-

decisiones-programacion-matematica.htm

Herbert, S. (1982). La nueva ciencia de la decisión gerencial. La nueva ciencia de la decisión gerencial. Buenos Aires, Argentina: El Ateneo.

Patarroyo, P. (s.f.). Teoría de decisiones. Retrieved May 23, 2007, from http://www.tuobra.unam.mx/publicadas/040922205227.html

Sánchez (2006), Teoría de las Decisiones. Ingeniería de Productividad y Calidad Facultad de Administración politécnico colombiano Jaime Isasa Cadavid.

Saaty, T. L. (2001). Decision Making with Dependence and Feedback: The Analytic Network Process (Second ed.). Pittsburgh, USA: RWS Publications, 4922 Ellsworth Avenue,Pittsburgh, PA 15213 USA. 
Urzúa, M. (2003). Cómo evaluar y seleccionar Cómo evaluar y seleccionar un ERP para su empresa un ERP para su empresa. Consideraciones relevantes para el Southern Domain Consulting Ltda. Retrieved June 7, 2008, from www.southerndDomain.com 